\title{
Abstraction Ability of Students About Fractions Through Local Cultural Approaches
}

\author{
Khathibul Umam Zaid Nugroho*, Wahyu Widada, Dewi Herawaty, Raudya \\ Tuzzahra, Berta Panduwinata, Nadya Sospolita
}

\author{
Postgraduate Mathematics Education Program, Universitas Bengkulu. Jl. WR. Supratman, Kandang Limun \\ Bengkulu, Indonesia 38371 \\ *Corresponding author. Email: khathibuluman.zn@unib.ac.id
}

\begin{abstract}
Fractions are concepts in mathematics which difficult for students to understand. Mathematical concepts are abstract. The purpose of this study was to describe students' abstraction abilities about fractions through a local cultural approach. It is exploratory research. The subjects of this study were 5 elementary school students. It is selected through a snowball technique. Task-based interviews were applied in this study. His job is to solve contextual problems about eating pizza in a family. In-depth interviews were conducted by researchers on research subjects. The result of the research is that students have reached the concept and principle of fractions correctly if the abstraction process starts from something close to the culture around the student. It is a horizontal mathematical process. Students are able to provide different but correct arguments to provide the right solution. The conclusion is that contextual problems trigger students to perform various abstraction processes. It can improve the ability to understand the concept of fractions.
\end{abstract}

\section{Keywords: Abstraction ability, Fractions, Contextual approach.}

\section{INTRODUCTION}

Mathematics is a subject that is difficult for students to understand. One of the reasons is the abstract objects [1]. These objects are facts, concepts, principles and operations. Facts are any convention about symbols. Abstract ideas for classifying mathematical objects are concepts. Statements that are true as attributes in mathematics are principles [2]. Whereas the rule for obtaining a single element from one or more other elements is called an operation. To achieve an understanding of these mathematical objects, good abstraction skills are required.

There are three mathematical process abilities that students must have. The three abilities are abstraction, idealization and generalization. Mathematical abstraction is an important process in mathematical thinking [3]. Therefore, an appropriate mathematics learning approach is needed. It is an approach that can make it easier for students to carry out the mathematical process horizontally towards vertical mathematics [4][5]. The process of abstraction becomes very dominant in reaching the right concept. In understanding the integral concept of a function, students often experience errors. One of the causes of this error is the low operability of fractions.

The results of the study found that students had errors in operating fractions such as $3 / 5-1 / 2=2 / 3$. He stated that the subtraction operation for the fraction was performed by subtracting the numerators, and denominators [6]. These errors were the result of misconceptions and principles in the operation of fractions. It's not just a computational error, or a miscalculation. In addition, there are many other mistakes in mathematics, including errors in understanding the problem. In solving math certain problems, there are students who wrongly determine what is known and what is asked. Often students do not write this down when they understand the questions. Fractions are one of the most difficult materials for elementary students. It is a concept that must be learned by students [6].

The concept of fractions is limited by a definition. A fraction is a number that can be written in the form $a / b$ with $a$, an integer, $b \neq 0$, and $b$ is not a factor of $a$ [7]. It is a rational number, plus the limitation that the denominator is not a factor of the numerator. There are seven sub-concepts of fractions [8]. First, a fraction is part of a congruent collection of parts. Part 
of the whole, with congruent divisions. Part of a collection of incongruent parts. Part of a collection by way of comparing. A fraction on a number line. Fractions are part of the whole by way of comparing. Also, fractions are part of the whole, with noncongruent divisions.

The abstraction ability of students often cannot cover the full complexity of the process as necessary and sufficiently necessary from mathematical concepts [9]. Therefore, a local culture-based learning approach is needed [10]. It is close to the student's mind, so that the learning trajectory becomes easier for students to carry out the abstraction process [6]. The student's cognitive process is getting better. Comprehensive understanding of cognition and learning in mathematics draws on various theoretical frameworks about abstraction.

Integrative learning improves students' abstraction abilities. Students have been able to integrate and formulate problems and transform problems into symbols. Students have been able to generalize, the formation of mathematical concepts related to other concepts [11]. Students can achieve concepts and principles through an empirical abstraction process. Students can use it to learn advanced mathematical concepts and have significant implications for educational practice [12].

Definition in mathematics is a limitation of a concept [13]. Mathematical objects are defined precisely according to mathematical terms. It uses colloquial words, but does not always have colloquial meanings. The syntax of mathematical arguments is different from the syntax of everyday language [14]. Visualization is often used by students, also in an abstraction process. Visualization used in the abstraction process helps understanding concepts [3]. Based on the description of rationality, the problem of this research is how the students' abstraction ability about fractions through a local cultural approach.

\section{METHOD}

Based on the problem, this study aims to describe the abstraction ability of students about fractions through a local cultural approach. It is a qualitative descriptive study with case studies. The subjects of this study were three students who were selected from 35 students. They are elementary school students in Bengkulu City. The selection is based on the results of completing the task on fractions. The tasks are: "On the table, pizza is served which is divided into 8 parts which are distributed to all family members. The family members consist of 5 people, namely father, mother and 3 children. How much does each family member get that portion of the pizza? Explain your opinion? " Five subjects selected have different answers. Furthermore, five subjects were interviewed in depth. To obtain accurate data, the interview process was recorded audio-visual. The data were analyzed qualitatively through the qualitative data analysis stage. It is data reduction, data display, and conclusion or verification [15].

\section{RESULTS AND DISCUSSION}

The operation to count fractions is one of the materials which is difficult for elementary students. To achieve the correct concept, students are asked to understand it through problems that are close to their thoughts. That is usually the dean with local culture. Each distribution of report cards for the results of the semester examinations of students is cultivated to share cakes. One of the cakes they bring is pizza. It becomes a local culture that is close to the minds of students. Through pizza culture, students are asked to complete assignments. Three research subjects were interviewed in-depth according to the results of the work on the paper. The three research subjects are S1, $\mathrm{S} 2$, and S3. The snippets of interviews with Researcher P are as follows.

Snippets of Interview with S1 Subject:

P: Please explain your work?

S1: In my opinion, father, mother and 3 children get $1 / 8$ and the remaining $3 / 8$ are saved for the next meal. Students give reasons that $1-(5 \times 1 / 8)=3 / 8$. He stated that $8 / 8-5 / 8=3 / 8$. You can see the Picture 1. 


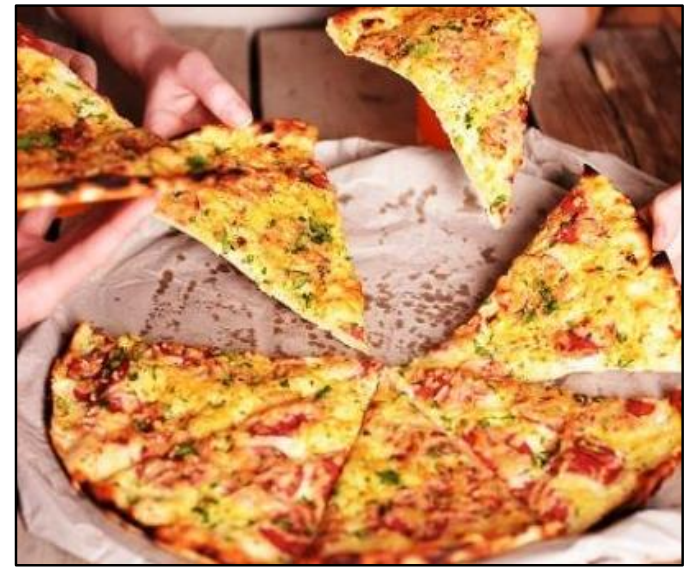

Figure 1. The pizza represented by $\mathrm{S} 1$

Based on snippets of interviews with $\mathrm{S} 1$ subjects and Figure 1, perform an abstraction using pizza using the Part-whole sub-concept, Congruent Part. It is an abstraction empirically, so that the fraction operation is well obtained. This abstraction is in accordance with the research [8] that the fraction subconcept shown in Figure 2 represents the area in red which is $3 / 4$ part of the whole. It is a part of the whole, by means of congruent division.

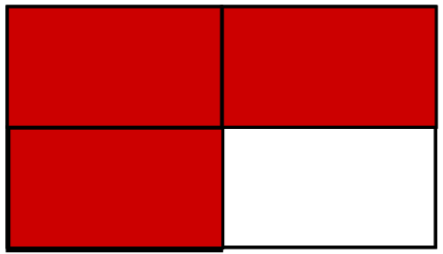

Figure 2. Part-whole, Congruent Part

also argues that $2 \times 1 / 8=2 / 8=1 / 4$, so $2 \times 1 / 8+3 \times 2 / 8$ $=1 / 4+3 x^{1 / 4}=1 / 4+3 / 4=4 / 4=1$.

Snippets of Interview with S2 Subject:

P: How was your job?

S2: I'm trying to solve it this way sir.

S2: Father and mother take 1/8 each, and the 3 children eat pizza each $1 / 4$ and there is no leftover. The reason is $2 \times 1 / 8+3 \times 2 / 8=2 / 8+6 / 8=8 / 8=1$. He
The $\mathrm{S} 2$ subject uses sub-concepts such as terera in Figure 3. This sub-concept is a fraction, part-group, congruent part sub-concept, namely $3 / 4$. It is the subconcept of fractions that is easiest for students to understand. The concept is built through a mathematical thinking process based on empirical things [2].
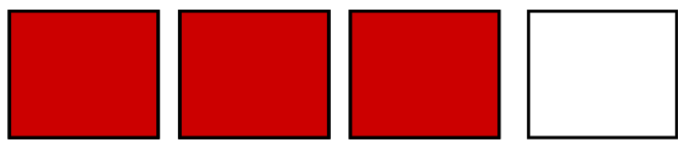

Figure 3. Part-group, Congruent Part

Figure 3 shows that, each part in the rectangular group is of the same shape and area, the only difference is the color. The red shape is $3 / 4$ part of the whole group of shapes. Spatially easy to understand. There are four congruent buildings. There are three red-colored buildings. The student can quickly state that the red buildings are three of the four parts of the group.
A different thing was conveyed by Subject $\mathrm{S} 3$. The answer is because hungry father eats Pizza $1 / 4$ and mother takes $1 / 8$, and the oldest son eats $1 / 8$ pizza and his two younger siblings each masing. The reason is $1-1 / 4-1 / 8-1 / 8-2 \times 1 / 4=8 / 8-2 / 8-1 / 8-1 / 8-2 \times 2 /$ $8=8 / 8-4 / 8-4 / 8=0$ This shows that S3 has been able to understand the concepts and principles of fractional operations. He equated the denominators and came up with a correct argument. 
The different answers from the three subjects illustrate that a real problem can be solved in different ways but all of them are correct. It depends on the arguments of the students. This illustrates that the fraction sub-concept that students understand provides the basic arguments for problem solving and the abstraction process carried out by students. [6]. Some of the other fraction sub-concepts are as follows.

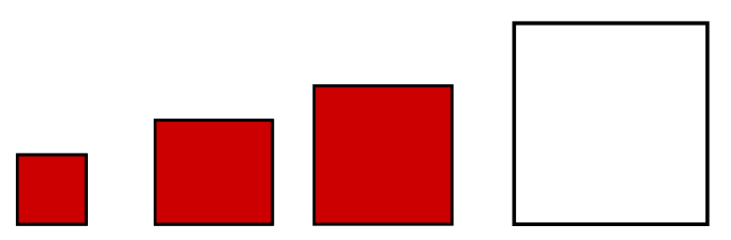

Figure 4. Part-group, Noncongruent Part

Based on Figure 4, the shapes in red are $3 / 4$ parts of a group, each part is not congruent. Figure 3 represents the concept of fractions that is more difficult than Figure 1 and Figure 2. Difficulties experienced by students because members of one

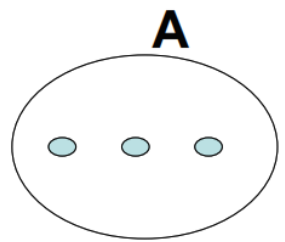

Figure 5. Part-group, Comparation

The number of members in Diagram $\mathrm{A}$ is $\mathrm{n}(\mathrm{A})=$ $3 / 4$ part of $n$ (B) (see Figure 5). It is done by comparing the number of members of $A$ with the number of members of $\mathrm{B}$. This concept relates to the another in the group are not congruent. Students will experience a higher level of difficulty if faced with the concept of fractions through parts of the set by comparing. Consider Figure 5.

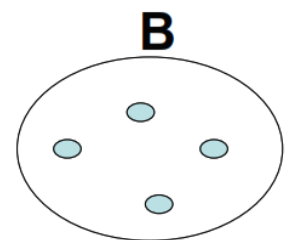

cardinality of a set. The cardinality of set $\mathrm{A}$ is $\mathrm{n}(\mathrm{A})=$ 3 and compared to $n(B)=4$, then $n(A)$ is $3 / 4$ part of $n$ (B).

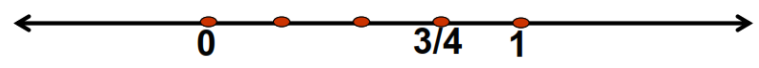

Figure 6. Number line

Figure 6 is a representation of $3 / 4$ as a dot on a number line. It shows the level of difficulty that is more representative of the previous
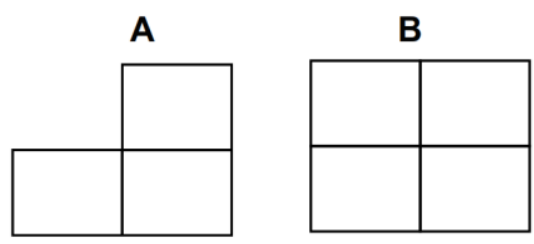

Figure 7. Part-whole, Comparation

Furthermore, students can understand the concept of fractions with a higher level of understanding than before. It is a representation of $3 / 4$ through the part of the whole by comparing two areas. 


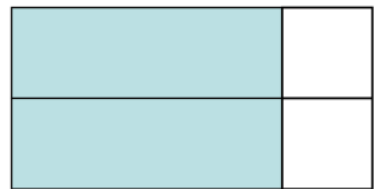

Figure 8. Part-whole, Noncongruent Part

Figure 8 is a representation of $3 / 4$ through the parts of the whole, with non-congruent divisions. This is the most difficult sub-concept for students to understand [9].

Abstraction is an important process in mathematical thinking [3]. The results of this study illustrate that learning through a local cultural approach and being close to students' minds makes it easier for students to abstraction from mathematical concepts [16]. This approach can also improve other math skills [17]. Through the ethnomathematics approach, students' genetic decomposition is more complete [18]. Thus, through a local cultural approach student is able to abstraction the concept of fractions appropriately. Students are able to provide arguments that are correct.

\section{CONCLUSIONS}

Fractions are a concept that must be understood by students. This study concludes that students can achieve the concepts and principles of fractions appropriately if the abstraction process starts from something close to the culture around the student. It is a horizontal mathematical process. Students are able to provide different but correct arguments to provide the correct solution. We suggest that math teachers start learning from something close to the student's culture.

\section{REFERENCES}

[1] W. Widada, K. U. Z. Nugroho, and W. Sari, "The Ability of Mathematical Representation through Realistic Mathematics Learning Based on Ethnomathematics," Semin. Adv. Math. Sci. Eng. Elem. Sch. Mercur. Hotel Yogyakarta, vol. 16, 2018.

[2] W. Widada, D. Herawaty, D. S. Andriyani, R. Marantika, and I. D. Yanti, "The thinking process of students in understanding the concept of graphs during ethnomathematics learning," IOP Conf. Ser. J. Phys. Conf. Ser. $1470 \quad 012072 \quad$ doilo.1088/17426596/1470/1/012072, vol. 1470, pp. 1-8, 2020.

[3] R. Yilmaz and Z. Argun, "Role of Visualization in Mathematical Abstraction: The Case of Congruence Concept," Int. J.
Educ. Math. Sci. Technol., pp. 1-1, 2017.

[4] D. Herawaty, W. Widada, A. Adhitya, R. D. W. Sari, and L. Novianita, "Students' ability to simplify the concept of function through realistic mathematics learning with the ethnomathematics approach," IOP Conf. Ser. J. Phys. Conf. Ser. 1470012031 doilo.1088/1742-6596/1470/1/012031, vol. 1470, pp. 1-8, 2020.

[5] W. Widada, D. Herawaty, Y. Beka, R. M. Sari, and R. Riyani, "The mathematization process of students to understand the concept of vectors through learning realistic mathematics and ethnomathematics," IOP Conf. Ser. J. Phys. Conf. Ser. 1470012071 doilo.1088/1742-6596/1470/1/012071, vol. 1470, pp. 1-10, 2020.

[6] W. Widada et al., "How are the process of abstraction of the division of fraction numbers by elementary school students?," Int. Semin. Appl. Math. Math. Educ. 2020 (2nd ISAMME 2020). J. Phys. Conf. Ser., vol. 1657, no. 012040, pp. 1-7, 2020.

[7] W. Widada, "Proses Pencapaian Konsep Matematika dengan Memanfaatkan Media Pembelajaran Kontekstual," J. Penelit. Pendidik. Mat. dan Sains, vol. 22, no. 1, pp. 31-44, 2015.

[8] H. Kurniawan et al., "Limited Intervention at Sub Concept of Fractions in the Object Conversion into Fractions," Int. Educ. Stud., vol. 9, no. 7, p. 145, 2016.

[9] D. Herawaty, W. Widada, H. Ardy, R. Furqany, and A. F. D. Anggoro, "The abstraction ability about natural numbers through playing traditional music for elementary students," Int. Semin. Appl. Math. Math. Educ. 2020 (2nd ISAMME 2020). J. Phys. Conf. Ser., vol. 1657, no. 012039, pp. $1-6,2020$.

[10] W. Widada, D. Herawaty, Y. Pusvita, D. Anggreni, R. Aripianti, and B. Panduwinata, "Multiplication and division of integers through cultural approaches of playing dakon," Int. Semin. Appl. Math. Math. Educ. 2020 (2nd ISAMME 2020), J. Phys. Conf. Ser., vol. 1657, no. 012030, pp. 1-9, 2020. 
[11] E. Komala, "Analysis of Students' Mathematical Abstraction Ability By Using Discursive Approach Integrated Peer Instruction of Structure Algebra Ii," Infin. J., vol. 7, no. 1, p. 25, 2018.

[12] J. Mason, "Mathematical Abstraction as the Result of a Delicate Shift of Attention Mathematical Abstraction as the Result of a Delicate Shift of Attention," Learn. Math., vol. 9, no. 2, pp. 2-8, 1989.

[13] W. Widada, Pendekatan Pembelajaran Matematika Berbasis Masalah. Surabaya: Unipa Press, 2004.

[14] M. Mitchelmore and P. White, "Abstraction in Mathematics and Mathematics Learning," Psychol. Math. Educ., vol. 3, pp. 329-336, 2004.

[15] M. B. Miles, A. . Huberman, and J. Saldana, Qualitative Data Analysis, A Methods Sourcebook,. USA: Sage Publications, 2014.

[16] D. Herawaty, W. Widada, K. Umam, Z. Nugroho, A. Falaq, and D. Anggoro, "The
Improvement of the Understanding of Mathematical Concepts through the Implementation of Realistic Mathematics Learning and Ethnomathematics," Adv. Soc. Sci. Educ. Humanit. Res. Vol. 295, vol. 295, no. ICETeP 2018, pp. 21-25, 2019.

[17] D. Herawaty, D. Khrisnawati, W. Widada, and P. Mundana, "The cognitive process of students in understanding the parallels axiom through ethnomathematics learning," IOP Conf. Ser. J. Phys. Conf. Ser. 1470012077 doilo.1088/1742-6596/1470/1/012077, vol. 1470, pp. 1-8, 2020.

[18] W. Widada, S. Efendi, D. Herawaty, and K. U. Z. Nugroho, "The genetic decomposition of students about infinite series through the ethnomathematics of Bengkulu , Indonesia," IOP Conf. Ser. J. Phys. Conf. Ser. 1470 012078 doilo.1088/17426596/1470/1/012078, vol. 1470, pp. 1-9, 2020. 